\title{
Vida Saludable: Anote su presión sanguínea ${ }^{1}$
}

\section{Leigh Ann Martin ${ }^{2}$}

Cada vez que usted se mide la presión sanguínea o se la mide un ENAFS

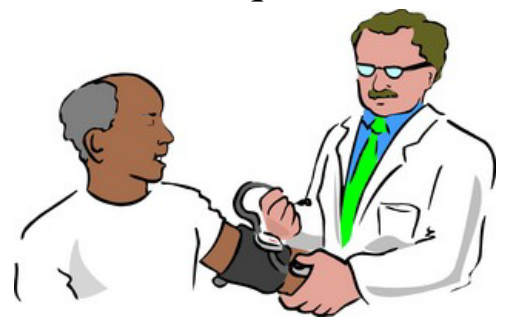
profesional de la salud, anote la fecha y hora, la lectura de la presión, donde fue medida (en casa, en la clínica del médico, etc.) y cualquier comentario que tenga usted o su profesional de la salud (por ejemplo, algún medicamento que está tomando o ha dejado de tomar, como se sentía en esa ocasión o el brazo en el que se hizo la medición).

\begin{tabular}{|l|c|l|l|}
\hline Fecha y Hora & Lectura & Lugar & Comentarios \\
\hline & $/$ & & \\
\hline & $/$ & & \\
\hline & 1 & & \\
\hline & 1 & & \\
\hline & 1 & & \\
\hline & 1 & & \\
\hline & 1 & & \\
\hline & 1 & & \\
\hline & 1 & & \\
\hline & 1 & & \\
\hline & & & \\
\hline
\end{tabular}

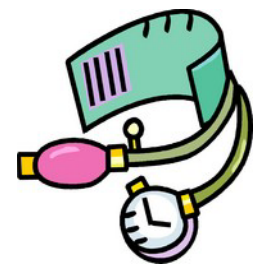

Si tiene preguntas sobre la presión sanguínea o como anotarla, háblele a su médico. Para ser referido a una dietista (RD) en su área, llame sin cargo a La Asociación Americana Dietética al 1-800-366-1655 (disponible en inglés y español).

1. The English version of this Spanish document is Healthy Living: Keep Track of Your Blood Pressure (FCS8601). Este documento, FCS8601Span, pertenece a una serie del Departamento de Ciencias de la Familia, Juventud y Comunidad, Servicio de Extensión Cooperativo de la Florida, Instituto de Alimentos y Ciencias Agrícolas, Universidad de la Florida, Gainesville, FL 32611. Fecha de Publicación: abril 2000. Revisado: octubre 2009. Favor de visitar el sitio de Internet de EDIS en http://edis.ifas.ufl.edu.

2. Leigh Ann Martin, anterior ENAFS educadora, Departamento de Ciencias de la Familia, Juventud y Comunidad, Servicio de Extensión Cooperativo de la Florida, Instituto de Alimentos y Ciencias Agrícolas, Universidad de la Florida, Gainesville, FL 32611.

El Instituto de Alimentos y Ciencias Agrícolas es una institución con igualdad de oportunidades, autorizado a proveer investigación, información educativa y otros servicios, únicamente a los individuos e instituciones que operan sin discriminación alguna con relación a la raza, credo, color, religión, edad, incapacidad, sexo, orientación sexual, estado civil, nacionalidad, opinión política o afiliaciones. El Departamento de Agricultura de los Estados Unidos, Servicio de Extensión Cooperativa, Universidad de la Florida, IFAS, Florida A. \& M. Programa de Extensión Cooperativa y Juntas de Comisionados del Condado en la cooperación. Millie FerrerChancy, Decana Interina 